\title{
The Valia-Kalda National Park, Greece
}

\author{
Gregory L. Tsunis
}

A dam is being built in Valia-Kalda, one of the ten national parks in Greece, despite the fact that this is not permissible under Greek law. Apart from the destruction caused by this activity, the park suffers from illegal hunting and over-grazing by livestock. The author, who was a member of two expeditions to Valia-Kalda in 1985 and 1986, describes the park, highlighting the features of special interest, and urges the Greek Government to safeguard it.

Greece has ten national parks, which together cover 160,000 ha, 0.5 per cent of the nation's land area. The Valia-Kalda National Park is the largest $(12,935$ ha), situated in Mount Pindos range in northern Greece (Figure 1). It lies between $1200 \mathrm{~m}$ and $2177 \mathrm{~m}$, and includes the Valia-Kalda valley and the slopes of Mts Avgo, Milià, Flegga and Aftià (Figure 2). Three streams (Valia-Kalda, Flegga and Arcoudorema) flow through the park and into the Aoös River. Although it was established in 1966, to protect some old Balkan pines Pinus heldreichii, it was poorly known until a party of four biologists, including myself, visited it in 1985 (3-15 July) and 1986 (8-14 September).

\section{The flora}

Large forests of black pine Pinus nigra and Balkan pine predominate, and many of the trees are more than 500 years old. On the northern slopes, below $1800 \mathrm{~m}$, these species are replaced by beech Fagus sylvatica. A few scattered Macedonian (or King Boris's) firs Abies borisii-regis can be found in both the pine and beech forests.

We found 40 individuals of Scots pine Pinus sylvestris in the locality Kokkina Pefka, close to the Arcoudorema stream. The discovery of this species in Valia-Kalda is of particular importance; the previously known southernmost points of its Valia-Kalda National Park, Greece range in the Balkan peninsula were further north on Mts Pieria and Olympus (Sfikas, 1978). ValiaKalda is the only place where the Scots pine can be found in the whole of Mount Pindos.

Many endemic plants of central and northern Greece grow in the park, for example Centaurea vlachorum, which was first discovered in the peaks of Mount Liggas and which has a very limited distribution. We discovered another

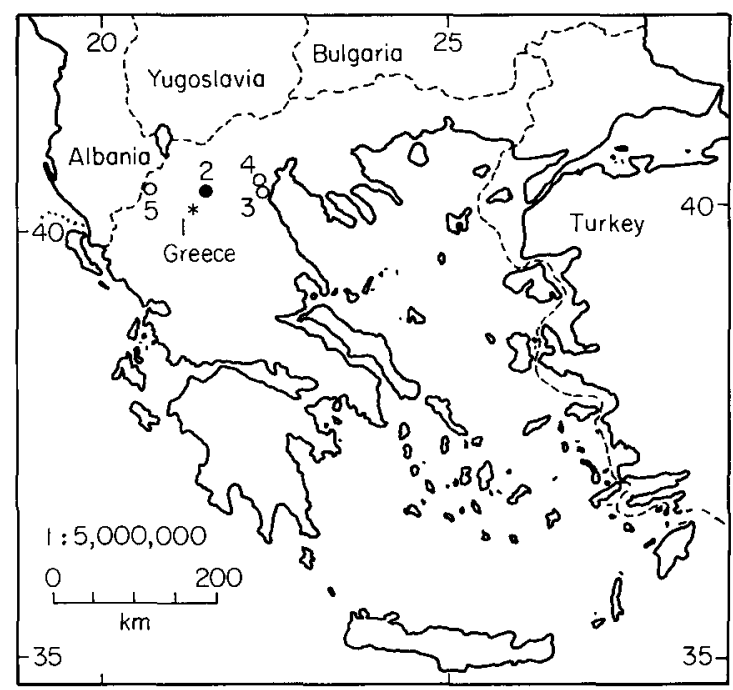

Figure 1. The Balkan peninsula showing the location of Valia-Kalda National Park and other places mentioned in the text: (1) The Valia-Kalda National Park,

(2) Grevena, (3) Mt Olympus, (4) Mt Pieria,

(5) Smolikas. 


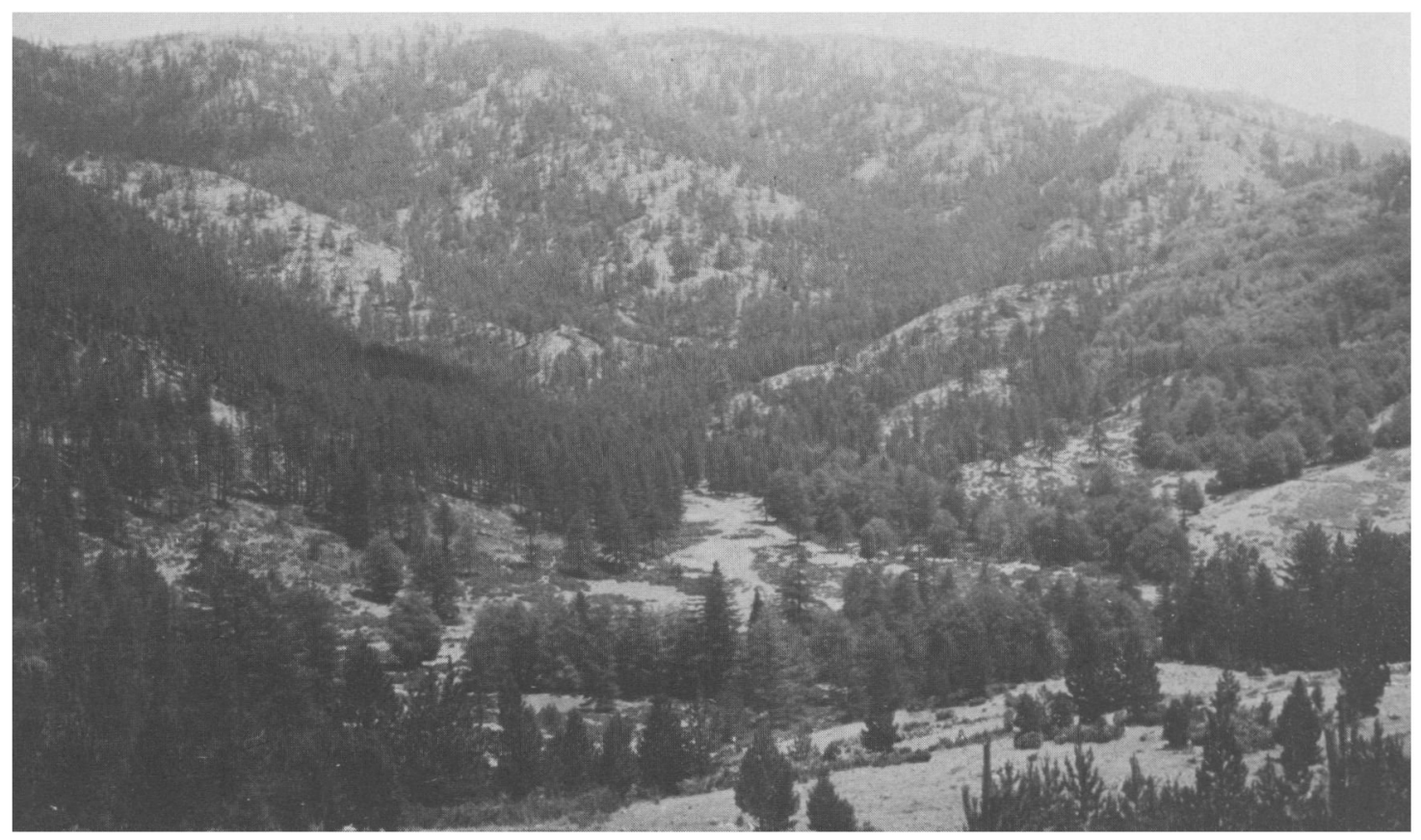

A view of Valia-Kalda National Park (G. Tsunis).

rare plant, Polygonatum verticillatum, in Limeria Tsanaka, which, according to Flora Europaea (Tutin et al., 1980), does not occur in Greece, although Polunin (1980) records it in Smolika, another peak of the Pindos range. We found Leucorchis frivaldii, a rare orchid of the Balkans, at $1900 \mathrm{~m}$ on Mt Flegga, and Onosma stellulata in Koufala, a species typical of southern Yugoslavia, and whose occurrence in Greece was uncertain. The most important areas for rare plants are the slopes of Aftià, Flegga, Kapetan Klidi, Kakopleuri and, in particular, the Koufala area.

\section{The fauna}

As far as birds are concerned, the presence of imperial eagle Aquila heliaca, griffon vulture Gyps fulvus, Egyptian vulture Neophron percnopterus and the rare lanner falcon Falco biarmicus, indicates the ornithological importance of the area. All these species are on The Red List of birds of Greece (Tsunis and Frugis, 1987). Another important feature is the occurrence of eight woodpecker species, out of the 10 recorded for the Western Palearctic (Cramp 26 and Simmons, 1985). The presence of the shore lark Eremophila alpestris and the great grey shrike Lanius excubitor is interesting. Both almost certainly nest here, and if this is confirmed for the shrike it would be a first record for Greece and the entire Balkan peninsula.

Brown bears Ursus arctos are present; we found their tracks near Salatura Papagianni at $1600 \mathrm{~m}$

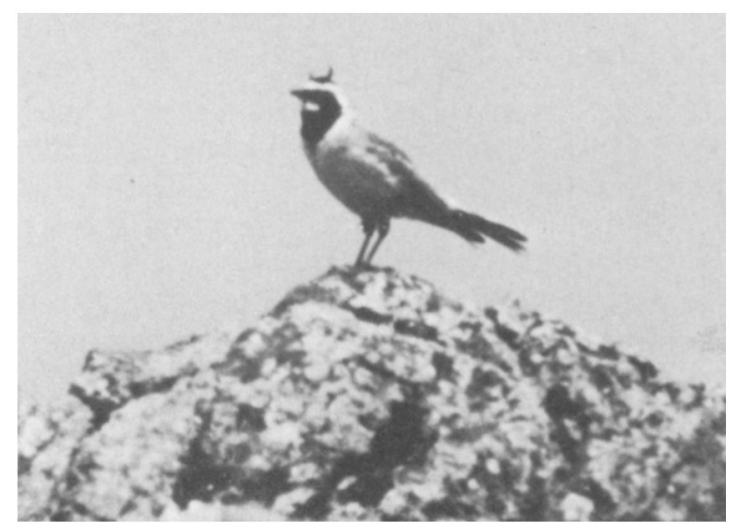

A shore lark-one of the park's breeding species-on the peaks of Mt Flegga ( $G$. Tsunis).

Oryx Vol 22 No 1, January 1988 
and also at Arcoudorema stream. Only a few wolves Canis lupus remain, as a result of persecution by man. We found otter Lutra lutra spraints in the Arcoudorema $(1200 \mathrm{~m})$ and in the Flegga streams (1400 m).

Other important mammals are wild cat Felis silvestris, chamois Rupicapra rupicapra and roe deer Capreolus capreolus, which are all found in the Flegga forest. The Valia-Kalda area and Flegga lakes have a very interesting amphibian fauna and some typical Balkan reptiles.

The results of our survey demonstrated very clearly that the entire Valia-Kalda area is of great importance to conservation, not only for Greece but also at a European level.

\section{Conservation problems}

The most pressing threat to the area is the construction of a dam by the Public Electric Company ( $\triangle \mathrm{EH}$ in Greek) in the very heart of the park. Despite local opposition works, which commenced in 1984, are still in progress. It is a typical example of the lack of co-ordination between the two government departments

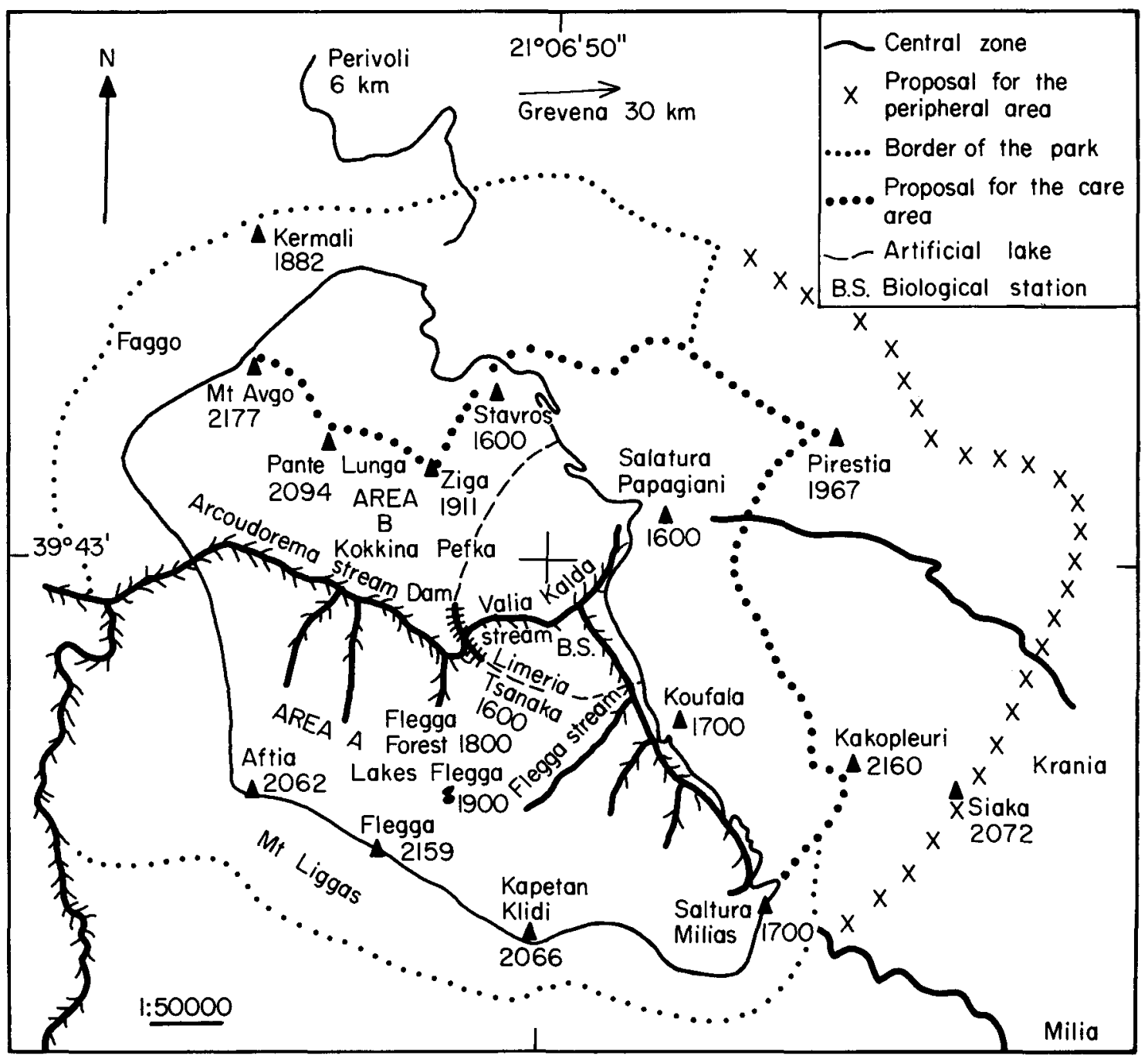

Figure 2. Valia-Kalda National Park. 


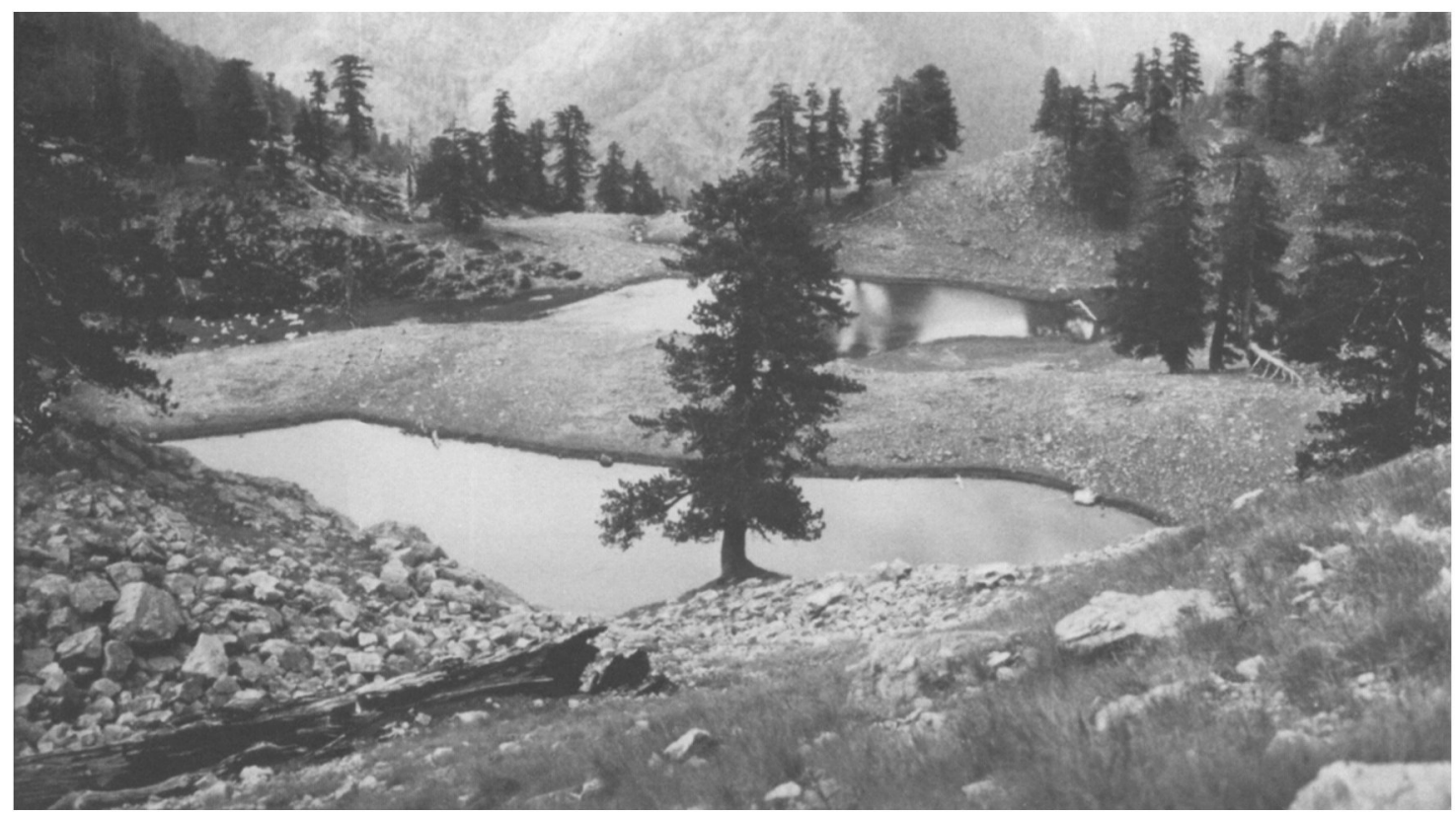

The Flegga Lakes in the park (G. Tsunis).

concerned. While the Ministry of Forestry and Agriculture wishes to implement a protection programme for the park, the Ministry of Energy wants the dam construction to continue. Already roads have been built and trees felled. On the slopes, soil is eroding, and trees and other plants are being uprooted in the process. If works continue, the consequences will be even more serious. The artificial lake created by the dam will cover part of the core area of the park, at present 6780 ha.

Another problem is sheep rearing, which is traditional in this part of the country and which is one of the main means of livelihood. More than 8000 sheep, goats and cattle graze in the park from May to September, being moved to the lowlands for the winter. The livestock trample and destroy the vegetation, especially in the passage-areas for the flocks and herds-Salatura Milias, Stavros, Salatura Papagianni.

Hunting, poaching and fishing with dynamite are everyday events. In summer many campers and hikers come from the surrounding villages to fish at Arcoudorema, and the dynamite they use destroys many fish and adversely affects the small otter population by depriving them of food. Every

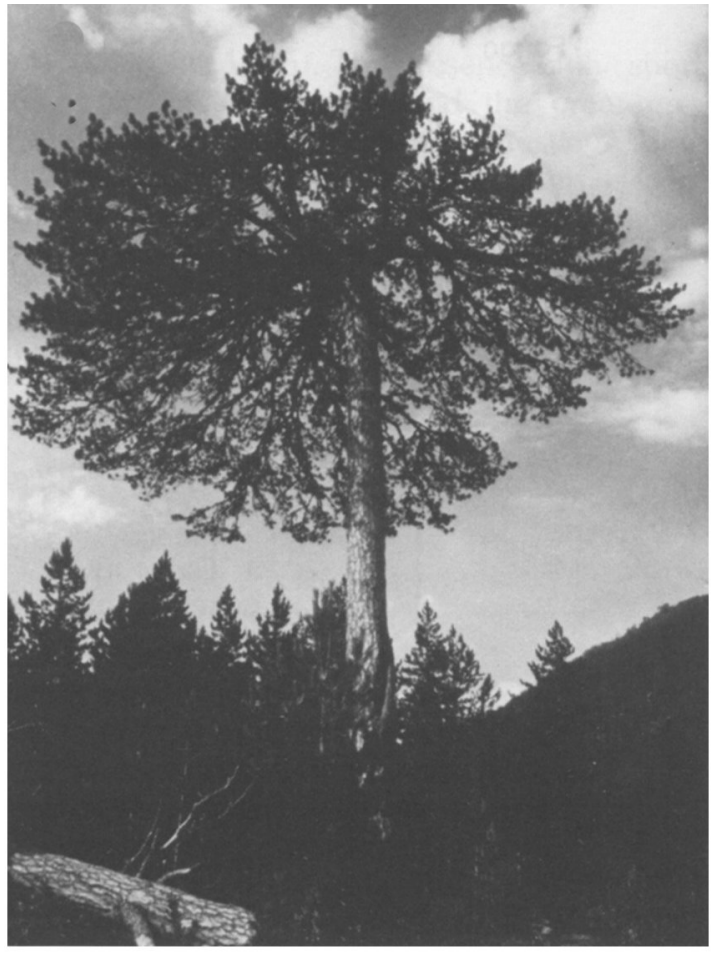

A black pine in Valia-Kalda National Park (G. Tsunis).

Oryx Vol 22 No 1, January 1988 
year shepherds kill many bears, which they say are a danger to their flocks. In addition, poachers kill bears, only to sell the bear skins for 70,000 drachmas each. Some bears also die because they eat dead animals poisoned with strychnine or other forbidden chemicals, which are used as bait for wolves.

Deforestation in the peripheral area of the park is another serious problem because it is uncontrolled and is gradually leading to soil deterioration.

\section{Recommendations}

In order to safeguard this important park we recommend the following action.

(i) Dam building should stop. The noise and impact of the machinery used will seriously disturb the wildlife, and the artificial lake will destroy a large and important part of the park. According to the Greek Park national law, every intervention within the central part of a park is strictly forbidden. Unfortunately this law seems to be totally disregarded in this case.

(ii) The Koufala area should be included in the park, and the eastern peripheral area widened.

(iii) A management group should be established under the direction of the Grevena Forestry Department. The group should contain a range of scientific specialists.

(iv) Naturalist guides should be employed to accompany visitors in the summer (winter visits are impossible because of snow cover). At least two wardens should be posted at each of the three natural entrances to the park (Stavros, Salatura Papagianni and Salatura Milias) and wooden bungalows should be built to serve as visitor centres.

(v) The number of sheep should be reduced to half the present number in the park and confined to the peripheral zone, particularly in the Mt Avgo area, while goats and cattle should be excluded altogether. In the northern part of the park only the Pante Lunga and Ziga peaks should be included in the central zone; the remaining area should be incorporated into the peripheral zone and returned to the shepherds. The State should compensate shepherds who lose sheep to bears. (vi) No further roads should be built in the park. (vii) The park's central zone should be divided into two areas: Area A, to include the southern Valia-Kalda National Park, Greece and south-eastern parts, and to be strictly protected and used only for scientific purposes; and Area $B$, which will be managed to conserve the park's various habitats. A Biological Station should be built in Area A as a facility for Greek and foreign researchers who wish to conduct biological studies in the park. It could become a study centre for the ecology of the bear, the chamois and the wolf, whose populations are threatened in Europe. The Biological Station could also operate a small meteorological unit.

(viii) In Perivoli, a village $6 \mathrm{~km}$ away, a Pindos Ethnological Research Centre could be set up to study the customs of the human population of $\mathrm{Mt}$ Pindos, particularly those of Vlachi, shepherds of Latin origins.

(ix) The town of Grevena, $30 \mathrm{~km}$ away, would be a good location for an exhibition relating to the natural history of the park, to inform local people and students.

(x) The most urgent need is to run a conservation education campaign for the park through any means possible, targetted especially at hunters and shepherds, and to press the Greek Government to safeguard the park.

\section{Acknowledgments}

I wish to thank Mr Byron Antipas, Hon. Gen. Secretary of the Hellenic Society for the Protection of Nature, for his help. A special thanks to Professor Sergio Frugis, Professor Sandro Lovari, George Sfikas, Mirsini Malakou, Maurizio Ravassini and Roberto Elettari.

\section{References}

Cramp, S. and Simmons, K.E.L. 1985. The Birds of the Westem Palaearctic, Vol. IV. Oxford University Press, Oxford.

Polunin, O. 1980. Flowers of Greece and the Balkans. Oxford University Press, Oxford

Sfikas, G. 1978. Trees and shrubs of Greece. Efstathiadis Group. Athens.

Tsunis, G. and Frugis, S. 1987. The Red List of Birds of Greece. Physis, Bull. Hell. Society for the Protection of Nature, 36: 20-21 and 29-34.

Tutin, T.G., Heywood, V.H., Burges, N.A., Moore, D.M., Valentine, D.H., Walters, S.M. and Webb, D.A. 1980. Flora Europaea. Vol. 5. Cambridge University Press. Cambridge.

Gregory L. Tsunis, Hellenic Society for the Protection of Nature, 24, Nikis str., 10557 Athens, Greece, or Centro Italiano Studi Omitologici, c/o Istituto di Zoologia, Universita di Parma, 43100 Parma, Italy. 